\title{
Genetic and Genomic Insights into the Role of Benzoate-Catabolic Pathway Redundancy in Burkholderia xenovorans LB400†
}

\author{
V. J. Denef, ${ }^{1,4}$ J. A. Klappenbach, ${ }^{1}$ M. A. Patrauchan, ${ }^{3}$ C. Florizone, ${ }^{3}$ J. L. M. Rodrigues, ${ }^{2}$ \\ T. V. Tsoi, ${ }^{1}$ W. Verstraete ${ }^{4}$ L. D. Eltis, ${ }^{3}$ and J. M. Tiedje $\mathrm{e}^{1,2 *}$ \\ Center for Microbial Ecology ${ }^{1}$ and Department of Microbiology and Molecular Genetics, ${ }^{2}$ Michigan State University, \\ East Lansing, Michigan 48824; Department of Microbiology and Immunology, University of British Columbia, \\ Vancouver, British Columbia V6T 1Z3, Canada ${ }^{3}$; and Laboratory of Microbial Ecology and \\ Technology, Ghent University, Ghent, Belgium ${ }^{4}$
}

Received 10 August 2005/Accepted 18 October 2005

\begin{abstract}
Transcriptomic and proteomic analyses of Burkholderia xenovorans LB400, a potent polychlorinated biphenyl (PCB) degrader, have implicated growth substrate- and phase-dependent expression of three benzoate-catabolizing pathways: a catechol ortho cleavage (ben-cat) pathway and two benzoyl-coenzyme A pathways, encoded by gene clusters on the large chromosome $\left(\right.$ box $\left._{C}\right)$ and the megaplasmid $\left(\right.$ box $\left._{M}\right)$. To elucidate the significance of this apparent redundancy, we constructed mutants with deletions of the ben-cat pathway (the $\triangle b e n A B C D:$ :kan mutant), the box ${ }_{C}$ pathway (the $\triangle$ box $A B_{C}:: k a n$ mutant), and both pathways (the $\triangle b e n A B C D \Delta$ box $A B_{C}:: k a n$ mutant). All three mutants oxidized benzoate in resting-cell assays. However, the $\triangle$ benABCD::kan and $\triangle$ ben-

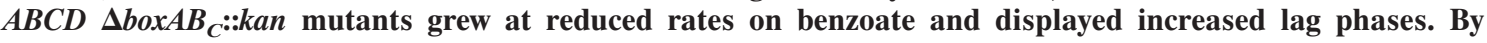
contrast, growth on succinate, on 4-hydroxybenzoate, and on biphenyl was unaffected. Microarray and proteomic analyses revealed that cells of the $\triangle$ ben $A B C D$ ::kan mutant growing on benzoate expressed both box pathways. Overall, these results indicate that all three pathways catabolize benzoate. Deletion of ben $A B C D$ abolished the ability of LB400 to grow using 3-chlorobenzoate. None of the benzoate pathways could degrade 2- or 4-chlorobenzoate, indicating that the pathway redundancy does not directly contribute to LB400's PCB-degrading capacities. Finally, an extensive sigmaE-regulated oxidative stress response not present in wild-type LB400 grown on benzoate was detected in these deletion mutants, supporting our earlier suggestion that the box pathways are preferentially active under reduced oxygen tension. Our data further substantiate the expansive network of tightly interconnected and complexly regulated aromatic degradation pathways in LB400.
\end{abstract}

Burkholderia xenovorans LB400 $(6,18)$ has been the focus of many studies over the past 2 decades due to its exceptional ability to transform polychlorinated biphenyls (PCBs) (11, 19, $33,38)$. Nonetheless, the PCB-degrading capacity is only one of many features of interest $(21,30,37,40,44)$ of this organism. The recent completion of the genome sequence of LB400 reveals that this organism has one of the largest bacterial genomes, which is $9.7 \mathrm{Mbp}$ in size and contains $\sim 9,000$ genes spread over two chromosomes (4.87 Mbp, 3.36 Mbp) and one megaplasmid (1.47 Mbp). Importantly, knowledge of the genome sequence has enabled us to initiate holistic experiments to investigate the underlying molecular factors contributing to LB400's ability to degrade PCBs.

Genomic analyses suggested that LB400 contains three benzoate-catabolic pathways: a ben-cat pathway and two box pathways. One of the latter is located on the large chromosome $\left(b_{C}\right)$, and the other is located on the megaplasmid $\left(\right.$ box $\left._{M}\right)$. The enzymes of these copies share 70 to $90 \%$ amino acid sequence identity to each other and 50 to $80 \%$ identity to the better-characterized Box enzymes of Azoarcus evansii (16, 17, $32,46,47)$. The catabolism of benzoate via the ben-cat pathway (20) consumes twice as much dioxygen as that via the box

\footnotetext{
* Corresponding author. Mailing address: Center for Microbial Ecology, 540 Plant and Soil Sciences Building, East Lansing, MI 48824 Phone: (517) 353-9021. Fax: (517) 353-2917. E-mail: tiedjej@msu.edu.

$\dagger$ Supplemental material for this article may be found at http://aem .asm.org/.
}

pathway. In the former, dioxygen is consumed by benzoate dioxygenase (Ben $\mathrm{ABC}$ ), which catalyzes the dihydroxylation of benzoate, and by catechol-1,2-dioxygenase (CatA), which catalyzes the ortho cleavage of catechol. In the box pathway, dioxygen is consumed in the BoxAB-catalyzed dihydroxylation of benzoyl-coenzyme A (CoA) to form 2,3-dihydroxybenzoylCoA $(17,47)$. Benzoyl-CoA is formed in an ATP-dependent reaction, and ring cleavage appears to be hydrolytic, leading to the formation of 3,4-dehydroadipyl-CoA semialdehyde and formate (16).

Previous transcriptomic and proteomic studies revealed that the expression of the ben-cat and box pathways in LB400 is strongly dependent on growth substrate and growth phase (12, 13). During exponential growth on benzoate, only the ben-cat pathway was detectably expressed. However, during the transition to stationary phase, the $b o x_{M}$ pathway was also expressed. Finally, during growth on biphenyl, the ben-cat and $b o x_{C}$ pathways were expressed. Nevertheless, these results do not conclusively show that each pathway assimilates benzoate.

Redundancy in peripheral metabolic pathways seems to be an important theme in this and other large-genome environmental isolates. While three different functional pathways for formaldehyde oxidation were observed in LB400 (30), studies with Rhodococcus sp. strain RHA1 ( $\sim 9.7 \mathrm{Mbp}$ ) have shown the presence of multiple pathways that catabolize phthalate, terephthalate, and ethylbenzene $(22,34)$. In Ralstonia eutropha JMP134 ( $7.3 \mathrm{Mbp})$, redundant tfd operons involved in 2,4dichlorophenoxyacetic acid degradation provide more-efficient 
degradation of 2-methyl-4-chlorophenoxyacetic acid (24), suggesting that the pathway redundancy confers a selective metabolic advantage.

Several studies have reported the occurrence of an oxidative stress response as a result of the presence or metabolism of aromatics. Increased amounts of reactive oxygen species and the concomitant increased expression of the general stress protein GroEL were observed in bacteria during biphenyl and PCB degradation (8). Other studies reported overlaps between the stress response to the presence of organochemicals and the responses to heat shock (5) or carbon starvation (45). In addition to GroEL, other factors presumed to be involved in the reduction of oxidative stress include alkylhydroxyperoxidases (27), ubiquinones (41), exopolysaccharide (EPS) production (9), and sigmaE-directed responses (43). In LB400, we have found increased protein levels of GroEL, AhpC, and HslU in response to oxidative stress during biphenyl or benzoate metabolism (13).

In this study, we deleted key dioxygenase genes in LB400 to investigate the role of each of the three apparent benzoate pathways in biphenyl and benzoate metabolism. The mutants were also used to evaluate the substrate ranges of these pathways towards other monoaromatic hydrocarbons. The transcriptomes and proteomes of the mutants were studied to obtain insights into the regulation of these pathways and their associated oxidative stress responses in order to provide new clues about the ecological significance of this pathway redundancy. Finally, we specifically investigated whether formate produced by box pathway activity is responsible for the $\mathrm{C}_{1}$ pathway induction observed earlier.

\section{MATERIALS AND METHODS}

Bacterial strains and genome sequence. Burkholderia xenovorans strain LB400 (previously Pseudomonas sp. strain LB400) originates from a PCB-contaminated New York State landfill site $(6,18)$. LB400's genome was sequenced at the Department of Energy's Joint Genome Institute and Lawrence Livermore National Laboratory and was automatically annotated by Oak Ridge National Laboratory's Computational Genomics Group. The latest sequence and draft analysis is available at http://genome.jgi-psf.org/finished_microbes/burfu/burfu home.html.

Media and growth conditions. LB400 and its deletion mutants were grown in liquid K1 mineral medium (48) supplemented with succinate $(10 \mathrm{mM})$, benzoate $(5 \mathrm{mM})$, particulate biphenyl $\left(5 \mathrm{mM}\right.$; solubility in water, $6.99 \times 10^{-3} \mathrm{~g} /$ liter $)$, 4-hydroxybenzoate $(5 \mathrm{mM})$, or 3 -chlorobenzoate $(3-\mathrm{CBA})(5 \mathrm{mM})$ as the sole carbon and energy source. Cells were grown at $29^{\circ} \mathrm{C} \pm 11^{\circ} \mathrm{C}$ on a rotary shaker at $250 \mathrm{rpm}$. For the determination of growth curves, cells were grown in $5 \mathrm{ml}$ medium in 18-mm by $150-\mathrm{mm}$ test tubes (Corning) and transferred in triplicate from a 5-ml succinate culture started from a glycerol stock. For resting-cell assays, microarrays, and proteomics, a glycerol stock was grown on R2A (Difco) agar plates, and for each biological replicate, a single colony was transferred to $5 \mathrm{ml} \mathrm{K} 1$ plus succinate liquid medium. One transfer was made in $5 \mathrm{ml} \mathrm{K} 1$ plus succinate, and then two transfers were made in $5 \mathrm{ml} \mathrm{K1}$-plus-benzoate medium. A final transfer was made into $200 \mathrm{ml} \mathrm{K} 1$ plus benzoate in 500-ml Erlenmeyer flasks. All transfers were made when the culture reached early stationary phase. For each strain (wild-type [wt], the $\triangle$ benABCD::kan mutant, and the $\Delta b e n$ $A B C D \triangle$ box $A B_{C}:: k a n$ mutant), two biological replicates were used for microarray analysis, and one was used for resting-cell assays. For proteomics on the benzoate-grown $\triangle$ ben $A B C D \triangle$ box $A B_{C}:: k a n$ mutant, three biological replicates were used. Cells were harvested at maximum growth rate (OD [optical density], $\sim 0.3$ ) or at the transition from logarithmic to stationary phase (OD, 0.96).

Genetics. Five gene deletion mutants were generated by use of the cre-lox recombination method described by Marx and Lidstrom (29): the first was the $\triangle$ benABCD::kan mutant, lacking the benzoate dioxygenase-encoding ben $A B C$ and benzoate cis-diol dehydrogenase-encoding benD; the second was the $\Delta$ box $A B_{C}:: k a n$ mutant, lacking the chromosomally located benzoyl-CoA oxygen- ase-encoding box $A B_{C}$; the third was the $\triangle$ ben $A B C D \triangle$ box $A B_{C}:: k a n$ mutant, lacking both ben $A B C D$ and $b o x A B_{C}$; the fourth was the $\triangle$ or815::kan mutant, lacking the gene encoding a LysR-type transcriptional regulator; and the fifth was the $\Delta$ or3163::kan mutant, lacking the gene encoding an ArsR-type transcriptional regulator (Table 1). A suicide vector that contains a R6K $\gamma$ origin of replication, pJK100, was constructed. The R6K $\gamma$ origin of replication requires the pir gene encoding the $\pi$ protein, which binds at a 22-bp recognition sequence to initiate DNA replication (31). The plasmid pJK100 (Fig. 1) was constructed by first excising a BsgI-AatII 1,674-bp fragment from pCM184 (29) containing the loxP$\mathrm{Km}^{\mathrm{r}}$-loxP element $\left(\mathrm{Km}^{\mathrm{r}}\right.$ is the kanamycin resistance gene) flanked by multiple cloning sites (MCS). The pCM184 BsgI-AatII fragment was subsequently blunt ended and ligated into an EcoRI-KpnI 2,180-bp blunt-ended fragment of pKNOCK-Tc (2). The resultant plasmid, pJK100, is 3,854 bp and carries a tetracycline resistance element, an R6K $\gamma$ origin of replication, the RP4 origin of transfer, and MCS-loxP-Km ${ }^{\mathrm{r}}$-loxP-MCS (Fig. 1). Plasmids with the R6K $\gamma$ origin of replication were propagated in a genetically modified Escherichia coli strain carrying the pir gene (WM3064; provided by W. Metcalf), which was also used to mobilize conjugative plasmids in recipient strains. Few bacterial strains carry the pir gene, making plasmids carrying the $\mathrm{R} 6 \mathrm{~K} \gamma$ origin of replication effective suicide vectors. The advantages of pJK100 are the $\mathrm{R} 6 \mathrm{~K} \gamma$ origin of replication, permitting broad host range applicability, and the small size of the vector $(3,854$ bp), which permits efficient conjugation into recipient strains. In addition to being used with B. xenovorans LB400 (class Betaproteobacteria), this system has been successfully used in our laboratory to delete genes from Shewanella oneidensis MR-1 (class Gammaproteobacteria).

The insertion of the PCR-generated flanking regions (primers in Table 1) of the genes targeted for deletion into pJK100 (intermediate and final constructs in Table 1 ) was performed as described previously $(29,30)$. For conjugation, LB400 was grown overnight in LB medium, of which $0.5 \mathrm{ml}$ was transferred to $10 \mathrm{ml}$ fresh LB. After 4 to $6 \mathrm{~h}$ of growth, 3 to $5 \mathrm{ml} \mathrm{LB} 400$ was combined with the donor strain Escherichia coli WM3064 at a ratio of 3:1; both strains were at an OD at $550 \mathrm{~nm}$ of $\sim 0.7$. The mixture was passed through a $0.45-\mu \mathrm{m}$ filter, which was placed on an LB agar plate and incubated for 20 to $22 \mathrm{~h}$ at $29 \pm 1^{\circ} \mathrm{C}$. The filter was placed in $10 \mathrm{ml}$ $\mathrm{LB}$, vortexed briefly, and then shaken for $40 \mathrm{~min}$ at $29 \pm 1^{\circ} \mathrm{C}$ and plated. Deletions were verified by PCR (Fig. 1) and sequencing. Using the procedure described by Marx and Lidstrom (29), the markerless strain VD114 was created by transfer (by conjugation) of the Cre enzyme-expressing pCM157 vector into strain VD114K, resulting in VD114K(pCM157). The Cre enzyme excises the fragment between the two Lox sites, i.e., the kanamycin resistance gene. A kanamycin-sensitive and tetracycline-resistant colony [VD114(pCM157)] was picked and cured from the pCM157 vector. This resulted in the markerless strain VD114, which was used for a second targeted gene deletion using the pJK100 derivative pVD214.

Resting-cell assays. Resting-cell assays and subsequent high-performance liquid chromatography (HPLC) analysis of (chloro)benzoates were performed as described previously (36) using wild-type LB400, the $\triangle$ benABCD::kan mutant, and the $\triangle$ ben $A B C D \triangle b o x A B_{C}:: k a n$ mutant. Cells were grown as described above and were harvested by centrifuging for $10 \mathrm{~min}$ at $1,500 \times \mathrm{g}$ and washed three times with $50 \mathrm{mM}$ phosphate buffer ( $\mathrm{pH} 7.0$ ). Cells were concentrated, resuspended in the same buffer to an OD at $600 \mathrm{~nm}$ of 1.0, and assayed in triplicate. By use of HPLC analysis, cells were assayed for metabolism of $0.5 \mathrm{mM}$ benzoate, 2-chlorobenzoate, 3-chlorobenzoate, or 4-chlorobenzoate.

Microarray analysis. RNA extraction and cDNA labeling using aminoallyl labeling were performed as described previously (12). The LB400 genomic microarray contains the same probes as the one described previously, (12), although divided in this case over only two XeoChips (Xeotron-Invitrogen), each containing $\sim 8,000$ in situ-synthesized 45-mers. On the basis of the current annotation, 556 genes $(6.2 \%)$, half of which are hypothetical, do not have a probe. Hybridizations were performed on an M-2 microfluidic station (Xeotron) according to the manufacturer's recommendations by use of a $100-\mu l$ hybridization solution with labeled cDNA containing $200 \mathrm{pmol}$ of each fluorescent dye per chip. Microarrays were scanned using an Axon 4000B (Axon Instruments) scanner, and data were extracted using Genepix 5.0 (Axon Instruments). Median signals for each channel (Cy5 and Cy3), after merging the two subchips of each biological replication, were imported into GeneSpring 6.0 (Silicon Genetics) and normalized using Lowess intensity-dependent normalization. $P$ values were calculated using GeneSpring's Student $t$ test algorithm based on the variation between $\log _{2}$ (ratio) values for biological replicates. To verify normalized data quality, plots for $M\left[M=\log _{2}(\mathrm{Cy} 5 / \mathrm{Cy} 3)\right]$ versus A $\left[\mathrm{A}=\log _{2}(\sqrt{(\mathrm{Cy} 5 \times \mathrm{Cy} 3)}]\right.$ were drawn for each biological replicate according to the method of Dudoit et al. (14). All normalized data from these microarray experiments as well as from microarray experiments performed previously on wt LB400 cells (12) are available as supplemental material.

Proteomic analysis. Cytosolic proteins were analyzed by two-dimensional gel electrophoresis (2DGE) followed by quantitative comparative analysis and ma- 
TABLE 1. Bacterial strains, primers and plasmids used in this study

\begin{tabular}{|c|c|c|}
\hline Strain, primer, or plasmid & Description $^{a}$ & Reference or source \\
\hline \multicolumn{3}{|l|}{ Strains } \\
\hline \multicolumn{3}{|l|}{ Burkholderia xenovorans } \\
\hline LB400 & Wild type & 6 \\
\hline VD114K & $\triangle b e n A B C D:: k a n$ & This study \\
\hline VD114 & $\triangle$ ben $A B C D$ & This study \\
\hline VD214K & $\Delta$ box $A B_{C}:: k a n$ & This study \\
\hline VD114-214K & $\triangle b e n A B C D \triangle b o x A B_{C}:: k a n$ & This study \\
\hline VD414K & $\Delta$ or815::kan (former or10103, encoding a LysR-type regulator) & This study \\
\hline VD514K & $\Delta$ or3163:kan (former or12426, encoding an ArsR-type regulator) & This study \\
\hline Escherichia coli WM3064 & $\begin{array}{l}\text { thrB1004 pro thi rpsL hsdS lacZ } \Delta M 15 \mathrm{RP} 4-1360 \Delta(\text { araBAD }) 567 \\
\quad \Delta \text { dapA1341::[erm pir] }\end{array}$ & W. Metcalf \\
\hline \multicolumn{3}{|l|}{ Primers } \\
\hline del1fluF & cgacagctcgtggaggctca & This study \\
\hline del1fluR & ACATATGggttgtctcctgacaatagtgcg & This study \\
\hline del1fldF & ACCGCGGcgctccaagcacgectgtc & This study \\
\hline del1fldR & AGAGCTCcggagccgtcgetgattgat & This study \\
\hline del2fluF & atgtccacgatcaactacagcg & This study \\
\hline del2fluR & ACATATGcgeccetcttccacattc & This study \\
\hline del2fldF & ACCGCGGgtgccgcetcacaatcgtc & This study \\
\hline del2fldR & AGAGCTCggctggatagccgcgtgaaa & This study \\
\hline del4fluF & tcgagatcgtcaacacaatgctg & This study \\
\hline del4fluR & GATGCGGCCGCtggttgtctcctgaacctttctgttttg & This study \\
\hline del4fldF & ACCGCGGgcggccatcgtatagcggaag & This study \\
\hline del4fldR & AGAGCTCctgcttcgcagccacagtgc & This study \\
\hline del5fluF & ccgcgaaaatcgagcaggtg & This study \\
\hline del5fluR & ACATATGgggtggctttcaaggtcttcaacaa & This study \\
\hline del5fldF & ACCGCGGcatcgecgcgettctttcat & This study \\
\hline del5fldR & AGAGCTCtttgcggaatgcttcgacca & This study \\
\hline $\operatorname{del} 1 \mathrm{~F}$ & gcgttcaccgaccetgetct & This study \\
\hline del1R & caggttgcgegagttctgga & This study \\
\hline $\operatorname{del} 2 \mathrm{~F}$ & ccgcggacgaactgtcgg & This study \\
\hline del2R & gctgetcgecgatctccttc & This study \\
\hline del4F & cettaccceggaaggcgaaa & This study \\
\hline del4R & tgcgccggagtatctgatcg & This study \\
\hline $\operatorname{del} 5 \mathrm{~F}$ & ctggctgcgtgagccgtatg & This study \\
\hline del5R & cgaggaacgectggatgacc & This study \\
\hline $\mathrm{kanF}$ & attgttgatgcgctggcagt & This study \\
\hline $\operatorname{kanR}$ & tccggtgagaatggcaaaag & This study \\
\hline \multicolumn{3}{|l|}{ Plasmids } \\
\hline pKNOCK-Tc & Allelic-exchange vector & 2 \\
\hline pCM184 & Allelic-exchange vector & 6 \\
\hline pJK100 & Allelic-exchange vector & This study \\
\hline pCM157 & Cre expression vector & 6 \\
\hline pCR2.1 & PCR cloning vector & Invitrogen \\
\hline pVD101 & pCR2.1 with ben $A B C D$ upstream & This study \\
\hline pVD102 & pCR2.1 with ben $A B C D$ downstream & This study \\
\hline pVD112 & pJK100 with ben $A B C D$ downstream & This study \\
\hline pVD114 & pVD112 with ben $A B C D$ upstream & This study \\
\hline pVD201 & pCR2.1 with box $A B_{C}$ upstream & This study \\
\hline pVD202 & pCR2.1 with box $A B_{C}$ downstream & This study \\
\hline pVD212 & pJK100 with box $A B_{C}$ downstream & This study \\
\hline pVD214 & pVD212 with box $A B_{C}$ upstream & This study \\
\hline pVD401 & pCR2.1 with or815 upstream & This study \\
\hline pVD402 & pCR2.1 with or815 downstream & This study \\
\hline pVD412 & pJK100 with or815 downstream & This study \\
\hline pVD414 & pVD412 with or815 upstream & This study \\
\hline pVD501 & pCR2.1 with or3163 upstream & This study \\
\hline pVD502 & pCR2.1 with or 3163 downstream & This study \\
\hline pVD512 & pJK100 with or3163 downstream & This study \\
\hline pVD514 & pVD512 with or3163 upstream & This study \\
\hline
\end{tabular}

${ }^{a}$ Capital letters in primer sequences indicate 5 ' extensions containing restriction enzyme recognition sites used for vector construction.

trix-assisted laser desorption ionization-time of flight analysis for protein identification as described earlier $(13,34)$. Briefly, cells were washed and disrupted in a lysis buffer using a bead beater. The first dimension was run using nonlinear Immobiline Dry (IPG) strips ( $24 \mathrm{~cm}$; $\mathrm{pH}$ values of 3 to 7 ) and $90 \mu \mathrm{g}$ of protein extract. The IPG strips were then run into $24-$ by $20-\mathrm{cm} 12 \%$ sodium dodecyl sulfate-polyacrylamide gels by use of an ETTAN DALTtwelve system (Amersham Biosciences). Protein spots were detected with Sypro ruby stain, and gels were imaged with a Typhoon 9400 instrument (Amersham Biosciences). Images 

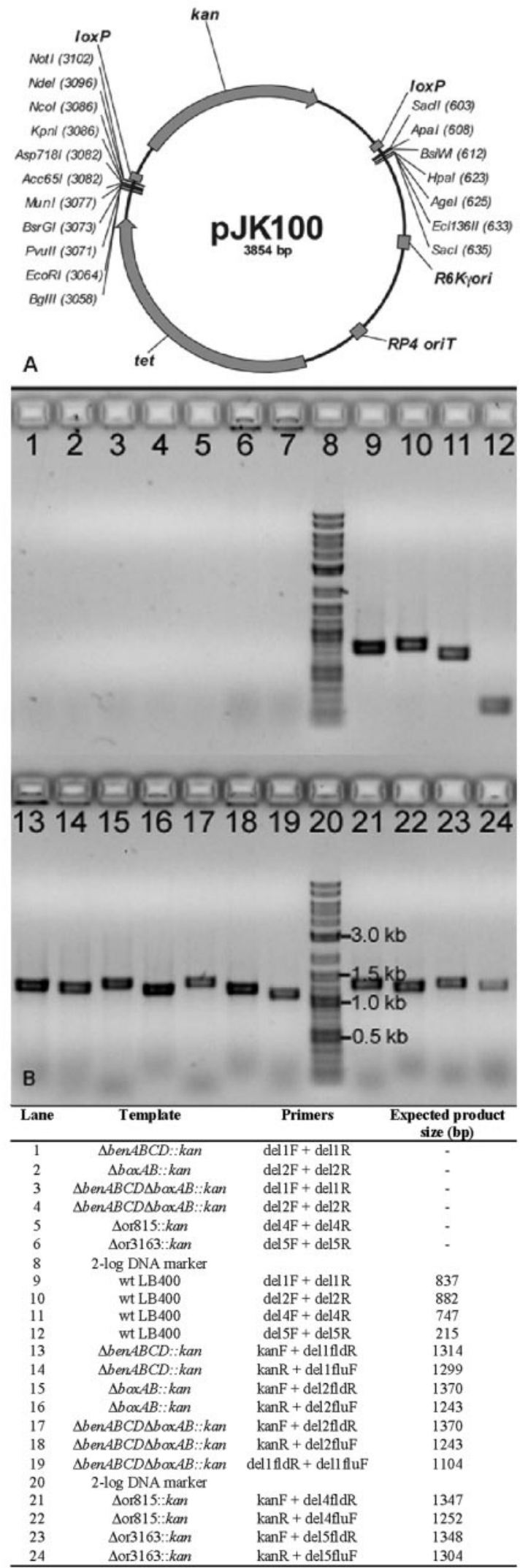

FIG. 1. (A) Suicide vector pJK100, used for targeted gene deletions, and (B) diagnostic PCR on the resulting deletion mutants of LB400. For the upper part of the gel, internal primers in the deleted were analyzed using Progenesis workstation software (Nonlinear Dynamics, Durham, NC). The normalized volume (NV) of a protein spot was calculated in Progenesis by dividing the volume of the protein spot by the total volume of all detected protein spots on a gel and multiplying by 100 . The averaged proteome profiles of the benzoate-grown $\triangle$ ben $A B C D \triangle$ box $A B_{C}:: k a n$ mutant and wt LB400 cells were quantitatively compared. Proteins of interest were identified on the basis of peptide mass fingerprint analyses (mass spectrometry) on a Voyager DESTR matrix-assisted laser desorption ionization-time of flight mass spectrometer (Applied Biosystems) by use of the Mascot search engine and the LB400 protein database.

Nucleotide sequence accession number. The pJK100 plasmid was sequenced at the Michigan State Genomics Facility and has been deposited in GenBank under accession number DQ157769.

\section{RESULTS}

Gene deletions. Gene deletions targeted key oxygenases of the ben-cat and box $_{\mathrm{C}}$ pathways. The following deletions were made: (i) $\triangle$ ben $A B C D:: k a n$, deleting genes encoding benzoate dioxygenase and benzoate cis-diol dehydrogenase; (ii) $\triangle b o x A B_{C}:: k a n$, deleting genes encoding the benzoate-CoA oxygenase of the chromosomally located $b o x_{C}$ pathway; and (iii) $\triangle b e n A B C D \quad \triangle b o x$ $A B_{C}:: k a n$, deleting both. Additionally, deletions were made for (iv) a LysR-type transcriptional regulator ( $\Delta$ or815::kan), which is coregulated with the biphenyl pathway (12), and (v) an ArsR-type transcriptional regulator ( $\Delta$ or3163::kan), which is coregulated with the ben-cat pathway (12). All the mutations (Table 1) were verified by PCR amplification (Fig. 1) and sequencing.

Benzoate pathway expression. Microarray hybridizations and 2DGE were used to determine the transcript and protein levels for the genes of the ben-cat, box ${ }_{C}$, and $b x_{M}$ pathways (Fig. 2A and B). Compared to what was seen with the benzoate-grown wild-type cells, both box pathways were induced when ben $A B C D$ was deleted. Additional deletion of box $A B_{C}$ resulted in reduced signals of those two transcripts and elimination of the previously identified BoxB protein. Remaining signals at the box $A B_{C}$ microarray probes were caused by crosshybridization of the box $A B_{M}$ transcripts to the box $A B_{C}$ probes. All other genes of the $b o x_{C}$ pathway remained expressed. On the basis of microarray and proteomic data, catechol 1,2-dioxygenase was equally expressed both in the $\triangle b e n A B C D:: k a n$ and $\triangle$ ben $A B C D \triangle$ box $A B_{C}:: k a n$ mutants and in wt LB400 cells. The $\beta$-ketoadipate pathway, however, was down-regulated at the transcript level. The latter was confirmed at the protein level for PcaF (Fig. 2A) in the $\triangle$ ben $A B C D \triangle b o x A B_{C}:: k a n$ mutant, which was in line with the overall consistency of the microarray and proteomic data for the $\triangle b e n A B C D$ $\triangle$ box $A B_{C}: \because k a n$ mutant (Fig. $2 \mathrm{~A}$ and B).

Deletion mutant characterization. The mutants with single and double knockouts of ben and $b o x_{C}$ retained the ability to grow on benzoate as the sole source of energy and carbon. However, extended lag times were observed for both the $\triangle b e n A B C D:: k a n$ mutant and the $\triangle$ ben $A B C D \triangle b o x A B_{C}:: k a n$ mutant (Fig. 3B). Moreover, the growth rates for these mutants were reduced when grown under the conditions for the

gene were used; for the lower part, a primer in the upstream or downstream region of the deleted gene and a primer inside the kanamycin resistance gene were used. (Bottom) The table indicates PCR templates and primers used and the expected PCR fragment sizes. 


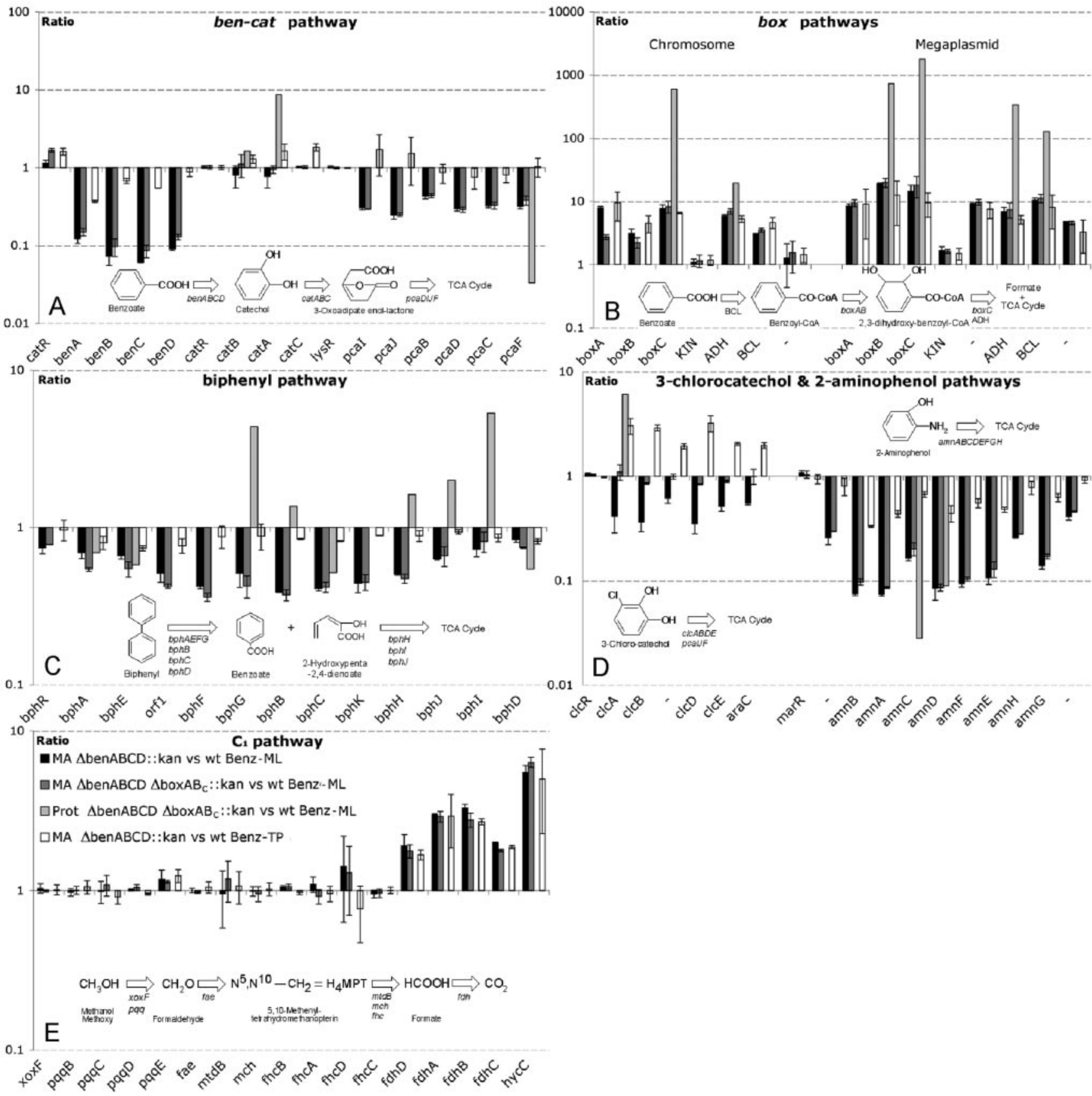

FIG. 2. Metabolic pathway gene expression ratios relative to wt LB400 for $\triangle b e n A B C D:: k a n$ (black) and $\triangle b e n A B C D \triangle b o x A B_{C}:: k a n$ (dark gray) mutants, all during mid-log-phase growth on benzoate (Benz-ML). Additionally, gene expression ratios for the $\triangle b e n A B C D:: k a n$ mutant relative to those for wt LB400, both from the transition phase after growth on benzoate (Benz-TP), are shown (white). If it was available, we presented the ratio of the NV of the protein spot on gels of mid-log-phase benzoate-grown $\triangle$ ben $A B C D \triangle b o x A B_{C}:: k a n$ mutant cells to the NV of the matched protein spot on wt LB400 gels (light gray). No protein spots of the gel for the $\triangle$ ben $A B C D \triangle b o x A B_{C}:: k a n$ mutant could be matched with previously identified spots on the wt LB400 benzoate gel for BenABCD and BoxB. (A) ben-cat pathway, including benzoate dioxygenase and $\beta$-ketoadipate pathway; (B) box ${ }_{C}$ pathway (left) and box ${ }_{M}$ pathway (right); (C) biphenyl pathway; (D) chlorocatechol (left) and aminophenol (right) pathways; and $(\mathrm{E}) \mathrm{C}_{1}$ metabolic pathway. Error bars indicate standard errors between biological replicates. TCA, tricarboxylic acid; KIN, kinase; ADH, aldehyde dehydrogenase; -, hypothetical protein; BCL, benzoate CoA ligase.

microarray, 2DGE, or resting-cell experiments $\left[R_{\max }\right.$ of LB400 $=$ $0.27 \pm 0.02$ cell division $/ \mathrm{h} ; R_{\max }$ of the $\triangle$ ben $A B C D:: k a n$ mutant $=$ $0.22 \pm 0.03$ cell division $/ \mathrm{h} ; R_{\max }$ of the $\triangle$ ben $A B C D \Delta b o x$ $A B_{C}:: k a n$ mutant $=0.16 \pm 0.01$ cell division $\left./ \mathrm{h}\right]$ (growth curves not shown). By contrast, disruption of one or both of these pathways did not detectably alter growth on succinate (a nonselective growth condition control) (Fig. 3A), biphenyl (Fig. 3C), or 4-hydroxybenzoate (Fig. 3D). However, growth on 3-chlorobenzoate required the presence of ben $A B C D$ (Fig. 3E). No significant effect on growth rate or lag time was observed 

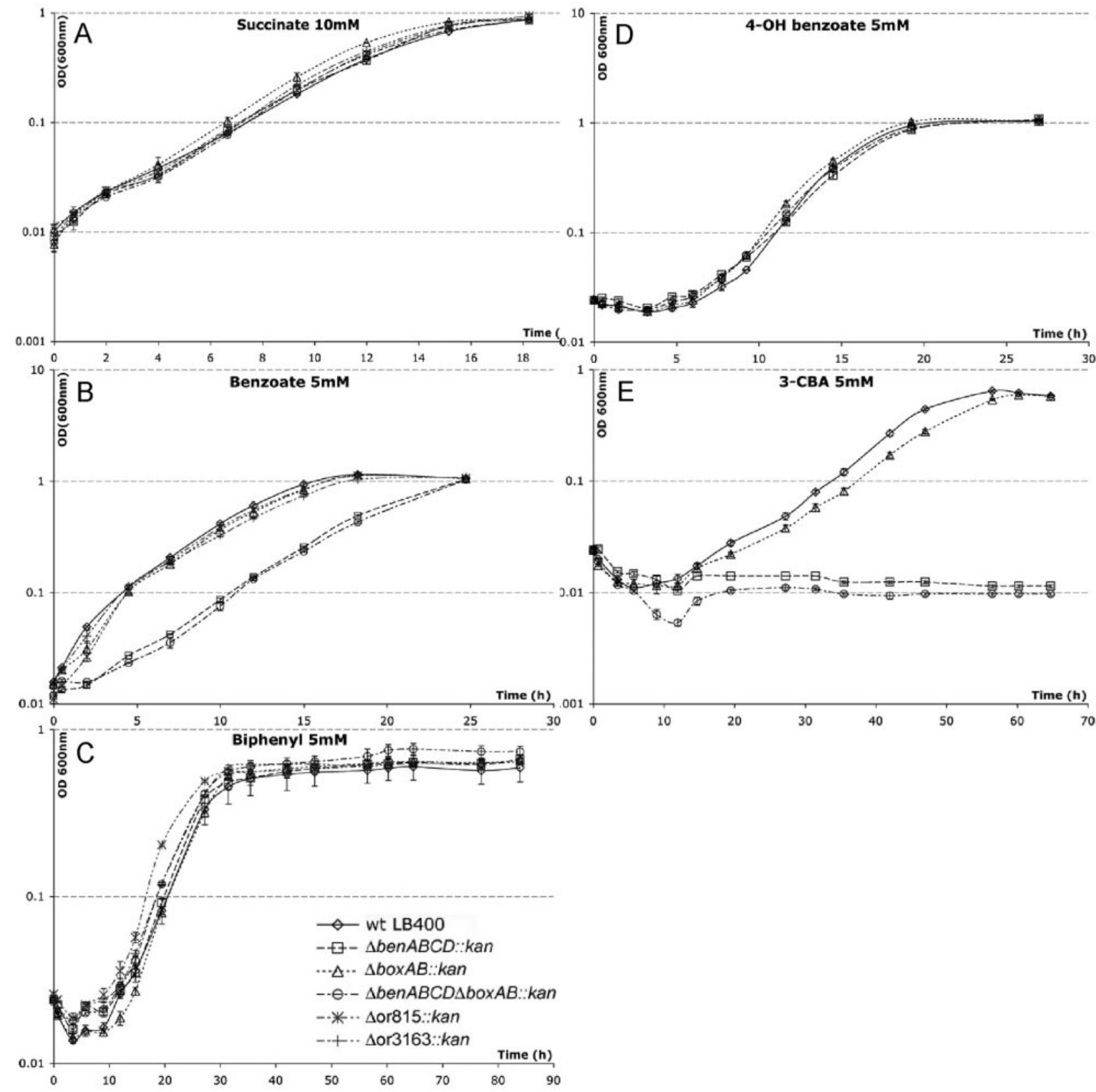

FIG. 3. Growth curves (OD at $600 \mathrm{~nm}$ versus time in hours) for cells of the wt LB400 ( $\diamond)$, the $\triangle b e n A B C D:: k a n$ mutant $(\square)$, the $\triangle b o x A B_{C}:: k a n$ mutant $(\triangle)$, the $\triangle$ ben $A B C D \triangle$ box $A B_{C}:: k a n$ mutant $(\bigcirc)$, the $\Delta$ or815::kan mutant (*), and the $\Delta$ or3163::kan mutant $(+)$ on succinate $(\mathrm{A})$, benzoate (B), biphenyl (C), 4-hydroxybenzoate (D), and 3-chlorobenzoate (E).

for the mutants with transcriptional regulator deletions $\Delta$ or815::kan and $\Delta$ or3163::kan grown under the tested conditions (Fig. 3A to C).

In resting-cell assays, wt and $\triangle$ ben $A B C D::$ kan and $\triangle b e n A B C D$ $\Delta$ box $A B_{C}:: k a n$ mutant cells removed benzoate from the medium (Fig. 4A). Taken together with the expression data presented above, this demonstrates that each of the three pathways degrades benzoate. By contrast, neither the wild type nor either of these mutants removed 2- or 4-CBA (Fig. 4C and D), which indicated that none of the three pathways oxidizes these compounds. Finally, 3-CBA was removed only by wild-type LB400 cells, i.e., when ben $A B C D$ was present.

Genome-wide peripheral effects of the gene deletions. The effects of the gene deletions were not limited to the targeted benzoate pathway expression. Including the benzoate pathway genes, 131 genes were at least twofold up-regulated and 54 were at least twofold down-regulated in the mid-log-phase $\triangle$ benABCD::kan mutant cells relative to mid-log-phase wt LB400 cells, with both grown on benzoate. Similarly, 121 genes were up-regulated and 59 down-regulated in mid-log-phase $\Delta b e n-$ 

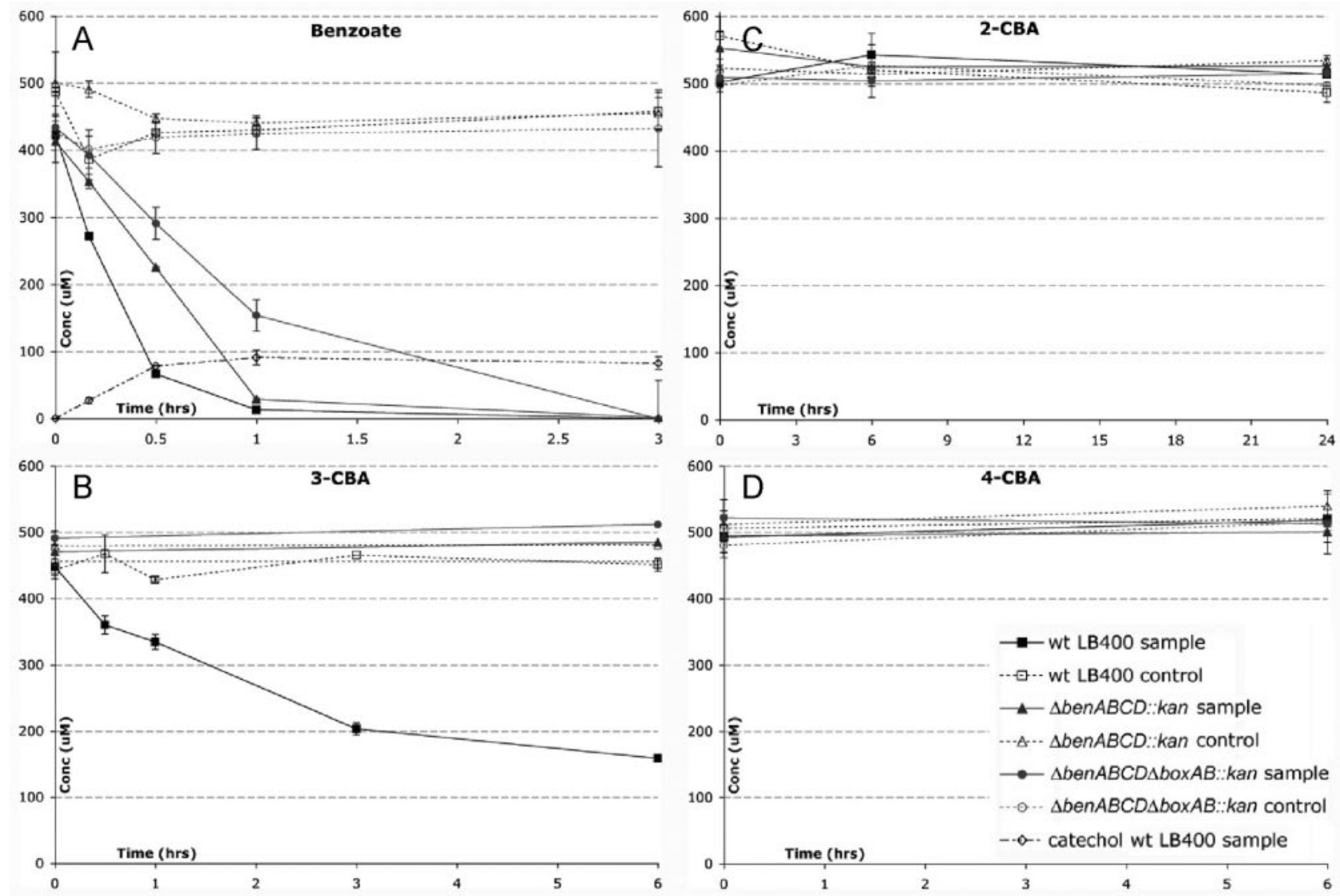

FIG. 4. Resting-cell assays on benzoate (A), 3-chlorobenzoate (B), 2-chlorobenzoate (C), and 4-chlorobenzoate (D) with resting (sample) or dead (control) cells (resuspended at an OD of 1), precultured on benzoate, of wt LB400 (resting, $\mathbf{\square}$; dead, $\square$ ) and the $\triangle$ benABCD::kan (resting, $\mathbf{\Delta}$; dead, $\triangle$ ) and $\triangle$ ben $A B C D \triangle$ box $A B_{C}:: k a n$ (resting, $\mathbf{0}$; dead, $\bigcirc$ ) mutants. Disappearance of the substrate (initial concentration $\left.=500 \mu \mathrm{M}\right)$ and accumulation of catechol (resting, $\diamond$ in panel A only) with standard errors between technical replicates are displayed as a function of time after incubation.

$A B C D \Delta$ box $A B_{C}:: k a n$ mutant cells. The responses to the single and double deletions were very similar, since a group of 105 genes was at least twofold up-regulated in both mutants compared to what was seen for wt LB400. In transition-phase benzoate-grown cells, 48 genes were up-regulated and 40 down-regulated in the $\triangle b e n A B C D:: k a n$ mutant relative to what was seen for transition-phase wild-type LB400.

Relative to wild-type cells, mutants exhibited reduced expression of the biphenyl pathway (Fig. 2C) during growth on benzoate, as measured by microarray hybridization. Proteomic data corroborated these results for BphA, BphE, BphC, and BphD. However, equal or increased protein levels were observed for BphG and BphB and for the lower biphenyl pathway enzymes $\mathrm{BphH}, \mathrm{BphJ}$, and BphI. Relative to mid-log-phase wt benzoategrown cells, where both the amn and clc pathways are expressed $(12,13)$, the 2-aminophenol ( $a m n)$ pathway was down-regulated in both mutants, while the 3-chlorocatechol ( clc) pathway was down-regulated in mid-log-phase $\triangle$ ben $A B C D:: k a n$ mutant cells, equally expressed in $\triangle$ ben $A B C D \triangle b o x A B_{C}:: k a n$ mutant cells (Fig. $2 \mathrm{D})$, and up-regulated in transition-phase $\triangle$ ben $A B C D:: k a n$ mutant cells. No differential expression of $\mathrm{C}_{1}$ metabolic pathways, except for the formate dehydrogenase $f d h$ genes (Fig. $2 \mathrm{E}$ ), was observed in any of the experiments. Relative abundances of the previously identified proteins of the amn, clc, and $\mathrm{C}_{1}$ pathways in the $\triangle$ ben $A B C D \triangle b o x A B_{C}:: k a n$ mutant compared to those in wt LB400 corresponded well with the microarray data (Fig. 2C to E).

Most genes previously related to an oxidative stress response in benzoate-grown wt LB400 cells were equally expressed or downregulated in the $\triangle b e n A B C D:: k a n$ and $\triangle b e n A B C D \triangle b o x A B_{C}:: k a n$ mutants (Table 2). This observation was confirmed with the protein levels for GroEL, HslU, and AhpF. At the same time, both mutants exhibited up-regulation of the cyo and tol genes. Approximately $13 \%$ of the genes at least twofold up-regulated in both mutants over wt levels could be attributed to a sigmaE-mediated stress response (Table 3).

\section{DISCUSSION}

The analysis of the three benzoate pathways in LB400 is a case study of functional redundancy, a recurring theme in studies of LB400 (30) and other large-genome environmental isolates $(22,24,34)$. Where previous studies $(12,13)$ suggested the involvement of the ben-cat, box ${ }_{C}$, and box $_{M}$ pathways in benzoate catabolism in LB400, the currently reported data provide definitive evidence that each pathway assimilates benzoate. Their stable cooccurrence in one organism and expres- 
TABLE 2. Potential oxidative stress response genes

\begin{tabular}{|c|c|c|c|c|}
\hline \multirow[b]{2}{*}{ Annotation } & \multirow[b]{2}{*}{$\mathrm{Gene}^{a}$} & \multicolumn{2}{|c|}{ Transcription level (ratio) for ${ }^{b}:$} & \multirow{2}{*}{$\begin{array}{c}\text { Translation (ratio) })^{c} \text { for } \\
\Delta \text { ben } A B C D \triangle \text { box } A B_{C}:: k a n \\
\text { mutant }\end{array}$} \\
\hline & & $\begin{array}{c}\Delta \text { benABCD::kan } \\
\text { mutant }\end{array}$ & $\begin{array}{c}\Delta b e n A B C D \triangle b o x A B_{C}:: k a n \\
\text { mutant }\end{array}$ & \\
\hline \multicolumn{5}{|l|}{ General stress response proteins } \\
\hline 60-kDa chaperonin (GroEL) & or7732 & $0.5(0.15)$ & $0.4(0.20)$ & 0.4 \\
\hline 10-kDa chaperonin (GroES) & or7733 & $0.8(0.63)$ & $0.5(0.31)$ & $\mathrm{n} / \mathrm{a}$ \\
\hline Putative DnaK suppressor & or8236 & $0.8(0.69)$ & $0.7(0.47)$ & $\mathrm{n} / \mathrm{a}$ \\
\hline$h s l V$ ATP-dependent protease & or8237 & $0.7(0.06)$ & $0.6(0.43)$ & $\mathrm{n} / \mathrm{a}$ \\
\hline$h s l U$ ATP-dependent protease & or8238 & $0.7(0.35)$ & $0.7(0.37)$ & 0.8 \\
\hline prkA serine kinase & or6208 & $2.2(0.03)$ & $3.1(0.04)$ & $123.5^{d}$ \\
\hline \multicolumn{5}{|l|}{ Alkyl hydroperoxide reductase $(a h p)$} \\
\hline$a h p C$ protein & or2448 & $0.8(0.28)$ & $0.8(0.25)$ & ND \\
\hline$a h p F$ protein & or2449 & No data & No data & 0.9 \\
\hline \multicolumn{5}{|l|}{ Cytochrome $o$ ubiquinol oxidase (cyo) } \\
\hline$c y o B$ protein & or2831 & $2.1(0.09)$ & $1.7(0.04)$ & $\mathrm{n} / \mathrm{a}$ \\
\hline cyo $A$ protein & or 2830 & $2.3(0.00)$ & $1.7(0.02)$ & $\mathrm{n} / \mathrm{a}$ \\
\hline cyo $C$ protein & or2829 & $2.1(0.06)$ & $1.6(0.01)$ & $\mathrm{n} / \mathrm{a}$ \\
\hline cyoD protein & or 2828 & $1.5(0.27)$ & $1.3(0.13)$ & $\mathrm{n} / \mathrm{a}$ \\
\hline \multicolumn{5}{|l|}{ tol (outer membrane stability) proteins } \\
\hline orf1 protein & or7816 & $1.4(0.26)$ & $1.1(0.35)$ & $\mathrm{n} / \mathrm{a}$ \\
\hline tolQ protein & or7817 & $1.2(0.25)$ & $1.0(0.10)$ & $\mathrm{n} / \mathrm{a}$ \\
\hline tolR protein & or7818 & $1.3(0.00)$ & $1.3(0.05)$ & $\mathrm{n} / \mathrm{a}$ \\
\hline tolA protein & or7819 & $1.4(0.18)$ & $1.1(0.33)$ & $\mathrm{n} / \mathrm{a}$ \\
\hline tolB protein & or7820 & $2.0(0.28)$ & $2.0(0.14)$ & $\mathrm{n} / \mathrm{a}$ \\
\hline Outer membrane lipoprotein & or7821 & $1.8(0.29)$ & $1.8(0.10)$ & $\mathrm{n} / \mathrm{a}$ \\
\hline Probable transmembrane protein & or7822 & $1.2(0.01)$ & $1.2(0.03)$ & $\mathrm{n} / \mathrm{a}$ \\
\hline
\end{tabular}

${ }^{a}$ The oxidative stress response proteins GroEL, HslU, PrkA, AhpC, and AhpF were more abundant in benzoate- and/or biphenyl-grown wt LB400 cells (13). Additionally, neighboring coexpressed genes and the tol and cytochrome $o$ ubiquinol oxygenase (cyo) operons, potentially involved in oxidative stress response, are listed.

${ }^{b}$ Gene expression ratios relative to wt LB400 cells, all during mid-log-phase growth on benzoate, with Genespring's Student $t$ test $P$ values in parentheses.

${ }^{c}$ If available, listed as the ratio of the NVs of the protein spot from the mid-log-phase benzoate-grown mutant to that for wt LB400. The percent standard error of the mean for the protein spots' averaged normalized volumes is below 6\%, and the $t$ test $P$ value for the ratios is below 0.03 . ND, protein was detected earlier in benzoate- or biphenyl-grown cells but was not detected on the two-dimensional gel for the mutant; n/a, protein was not identified on any of the two-dimensional gels.

${ }^{d}$ Protein spot was not detected in mid-log-phase benzoate-grown wt LB400 cells. A normalized volume of 0.002 was used for calculation of the ratio.

sion under different conditions suggests that this functional redundancy confers a competitive advantage. For example, differential regulation may ensure optimal metabolic integration depending on the available substrates (particularly in mixtures of aromatics or at different oxygen tensions) as well as the physiological state of the cell.

The initial substrate range experiments provide some interesting insights. Under the tested conditions, the ben-cat pathway most rapidly converted benzoate (resting-cell assays) and resulted in the most rapid growth (growth experiments). However, it was characterized by some losses, since catechol was found to accumulate in the medium when growing wt LB400 on benzoate (data not shown) as well as in resting-cell assays on benzoate (Fig. 4A). The lack of effect of the benzoate pathway deletions on cell growth on 4-OH benzoate was expected, since 4-OH benzoate is metabolized via mono-oxygenation and the protocatechuate pathway (20). The lack of differences between the growth of wt LB400 and that of the $\triangle b e n A B C D:: k a n$ and $\triangle b e n A B C D \triangle b o x A B_{C}:: k a n$ mutants on biphenyl was more surprising, since the ben-cat and box $x_{C}$ pathways were the only two benzoate pathways proven to be expressed during biphenyl growth by combined microarray (12) and proteomic (13) data. This indicates that the absence of the normally expressed pathways does not create a metabolic bottleneck under the tested conditions.
Our results also showed that this benzoate pathway redundancy does not play a direct role in the potency of LB400 as a PCB degrader $(4,28)$. The sole monochlorobenzoate to be degraded (CBAs are the main metabolites of PCBs) was 3-CBA. The fact that the inability to grow on or degrade 3-CBA by preinduced enzymes when benzoate dioxygenase was deleted, even though the $c l c$ pathway was equally expressed in $\triangle$ ben $A B C D \triangle b o x A B_{C}:: k a n$ mutant and wt LB400 cells, indicated that the box benzoate CoA ligases are unable to use chlorobenzoates as a substrate. Earlier, 30 to $40 \%$ degradation of 2-CBA was reported from resting-cell assays with transition-phase biphenyl-grown wt LB400 cells (28). Since our resting-cell assays with benzoate-grown wild-type and mutant cells demonstrated no 2-CBA degradation, this conversion should not be linked to benzoate pathway activity but rather to the activity of other metabolic pathways induced during biphenyl growth. A high number of metabolism-related genes are indeed up-regulated during biphenyl growth, particularly in transition growth phase (12). However, none of these genes have previously been linked to chlorinated benzoate degradation. Most noticeable is a group of genes involved in $\mathrm{C}_{1}$ metabolism, which is specifically expressed in transition-phase biphenyl-grown cells, except for the formate dehydrogenase genes. The latter were expressed only when the box pathways were active (Fig. 2E), presumably as a result of formate pro- 
TABLE 3. SigmaE-dependent response in LB400, based on the sigmaE-dependent transition to the mucoid state of Pseudomonas aeruginosa ${ }^{a}$

\begin{tabular}{|c|c|c|c|c|}
\hline \multirow[b]{2}{*}{ Annotation } & \multirow[b]{2}{*}{$\mathrm{Gene}^{b}$} & \multicolumn{3}{|c|}{ Ratio to ${ }^{c}$ : } \\
\hline & & $\begin{array}{c}\begin{array}{c}\Delta b e n A B C D:: k a n \\
\text { mutant }\end{array} \\
\text { unt }\end{array}$ & $\begin{array}{c}\Delta b e n A B C D \triangle b o x A B_{C}:: k a n \\
\text { mutant }\end{array}$ & $\begin{array}{l}\text { Mucoid } \\
\text { P. aeruginosa }\end{array}$ \\
\hline \multicolumn{5}{|l|}{ SigmaE operon encoding: } \\
\hline RNA polymerase sigma-24 factor $(r p o E)$ & or5406 & $3.1(0.00)$ & $2.9(0.00)$ & 49.2 (PA0762) \\
\hline SigmaE factor transcription regulator $($ mисB) & or5408 & $1.9(0.02)$ & $1.8(0.05)$ & 7 (PA0764) \\
\hline Serine protease $(m и с D)$ & or5409 & $1.6(0.00)$ & $1.6(0.02)$ & $2.2(\mathrm{PA} 0766)$ \\
\hline \multicolumn{5}{|l|}{ Proven sigmaE-regulated genes encoding ${ }^{d}$ : } \\
\hline Probable transmembrane protein & or5820 & $2.3(0.05)$ & $2.4(0.04)$ & 56 (PA3819) \\
\hline Osmotically inducible protein OsmC & or2394 & $1.8(0.04)$ & $1.7(0.10)$ & 24 (PA0059) \\
\hline Putative UDP-glucose dehydrogenase & or6421 & $4.3(0.00)$ & $4.0(0.00)$ & 7 (PA3540) \\
\hline RNA polymerase sigma-32 factor $(r p o H)$ & or8023 & $1.6(0.17)$ & $2.3(0.09)$ & 1 (PA0376) \\
\hline \multicolumn{5}{|l|}{ Probable sigmaE-regulated genes encoding ${ }^{d}$ : } \\
\hline Putative transmembrane protein & or1726 & $4.4(0.07)$ & $4.4(0.06)$ & 18 (PA5182) \\
\hline $\mathrm{ABC}$ transporter & or4051 & $1.3(0.02)$ & $1.4(0.00)$ & 11 (PA3890) \\
\hline Probable transmembrane protein & or7810 & $1.6(0.00)$ & $1.4(0.15)$ & 6 (PA3041) \\
\hline Putative $\mathrm{Mg}^{2+}$ transporter & or6390 & $0.9(0.15)$ & $0.9(0.76)$ & 4 (PA2148) \\
\hline Outer membrane lipoprotein & or8008 & $1.0(0.65)$ & $1.0(0.47)$ & 0.25 (PA4668) \\
\hline \multicolumn{5}{|l|}{ EPS production genes encoding ${ }^{d}$ : } \\
\hline Putative UDP-glucose dehydrogenase ( $\operatorname{llg} D$-like) & or6421 & $4.3(0.00)$ & $4.0(0.00)$ & 7 (PA3540) \\
\hline Putative undecaprenylphosphate glucose phosphotransferase & or6422 & $2.5(0.03)$ & $2.2(0.15)$ & \\
\hline Putative mannose-1-phosphate guanylyltransferase (algA-like) & or6423 & $1.9(0.13)$ & $2.0(0.02)$ & 4.3 (PA3551) \\
\hline \multicolumn{5}{|l|}{ Pyoverdin biosynthesis genes encoding ${ }^{d}$ : } \\
\hline Formyltransferase $(p v d F)$ & or1826 & $5.3(0.02)$ & $5.1(0.01)$ & \\
\hline L-Ornithine 5-mono-oxygenase ( $p v d A)$ & or1825 & $2.4(0.00)$ & $2.5(0.05)$ & \\
\hline Nonribosomal peptide synthetase ( $p v d I J D)$ & or1824 & $2.0(0.00)$ & $2.3(0.00)$ & 4 (PA2305) \\
\hline Nonribosomal peptide synthetase ( $p v d L$ ) & or1823 & $1.5(0.01)$ & $1.5(0.07)$ & 5 (PA3327) \\
\hline $\mathrm{ABC}$ transporter $(p v d E)$ & or1822 & $2.1(0.07)$ & $2.4(0.00)$ & \\
\hline \multicolumn{5}{|l|}{ Flagellar biosynthesis genes encoding: } \\
\hline Flagellar basal body rod protein $(f g E)$ & or4572 & $0.5(0.07)$ & $0.3(0.05)$ & 0.59 (PA1080) \\
\hline Type II flagellin $(f l i C)$ & or4535 & $0.5(0.21)$ & $0.4(0.08)$ & 0.34 (PA1092) \\
\hline Flagellar hook-associated protein $2(f l i D)$ & or4534 & $0.6(0.01)$ & $0.6(0.01)$ & 0.53 (PA1094) \\
\hline
\end{tabular}

${ }^{a}$ Based on data from Firoved and Deretic (15).

${ }^{b}$ LB400 genes listed are the best BLAST hits for the $P$. aeruginosa genes. Additional genes for EPS biosynthesis (organized as a cluster of $\sim 30$ coexpressed genes in LB400, half of which were significantly $[P<0.05]$ up-regulated in either LB400 mutant) and pyoverdin biosynthesis are given.

${ }^{c}$ Microarray expression ratios are relative to wt LB400 for $\triangle$ ben $A B C D:: k a n$ and $\triangle$ ben $A B C D \triangle b o x A B_{C}:: k a n$ mutants-all during mid-log-phase growth on benzoateand to nonmucoid $P$. aeruginosa data from Firoved and Deretic (15). Between parentheses we added the $P$ values for our expression data or the $P$. aeruginosa gene accession numbers from the data from Firoved and Deretic.

${ }^{d}$ Proven means shown to be sigmaE regulated by means other than microarrays. Probable means shown to be sigmaE regulated by the microarray experiments of Firoved and Deretic (15). EPS cluster includes homologs for sigmaE-regulated $\operatorname{llg} A$ and $\operatorname{alg} D$. SigmaE-regulated pyoverdin synthesis genes as described by Ravel and Cornelis in $2003(35)$

duction by this pathway (16). The data from the microarray experiment comparing the transition-phase benzoate-grown $\triangle$ ben $A B C D:: k a n$ mutant to wt LB400 conclusively show that box pathway activity and the resulting formate production and possible accumulation are not the trigger for the complete $\mathrm{C}_{1}$ pathway induction.

We already noted some interactions in pathway regulation in LB400, e.g., the observed coexpression of the 2-aminophenol and 3-chlorocatechol pathways with the ben-cat pathway in benzoate-grown cells (12). The mutants' expression patterns of the different components of the ben-cat, bph, amn, and $c l c$ pathways are further indications of the complexity and interconnection of the regulatory networks for these pathways. Cross talk between the regulation of different metabolic pathways has been reported before, as summarized in reference 7 . Supposedly, certain intermediates, such as cis,cis-muconate (20) or even benzoate itself in the case of the biphenyl pathway, act as effectors in the transcriptional regulation network.
From the expression patterns, we can deduce that benzoate is an inducer for the catABC and clc genes, while a ben-cat pathway intermediate is an inducer for the pca and amn genes. The deletion mutants we made of the LysR ( $\Delta$ or815::kan)- and

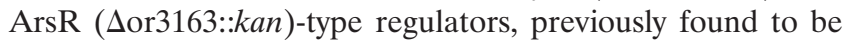
coregulated with the biphenyl pathway and the ben-cat pathway, respectively (12), did not show any phenotype in the tested conditions but do remain candidates to be part of this network. Similar to what has been observed with wt cells, discrepancies occur between the transcript and protein levels of $\mathrm{BphG}$ and $\mathrm{BphB}$ and the lower $b p h$ pathway proteins BphHJI. The mechanism underlying these phenomena is unclear. In the case of CatA, the current data as well as previous comparisons between transcript and protein data (13) indicate Cat $\mathrm{A}$ is more stable than the other Cat proteins, although the possibility that other factors are involved as well and result in this discrepancy cannot be excluded.

When wt LB400 assimilates benzoate during logarithmic 
growth, it uses only the ben-cat pathway, which results in a limited stress response that involves general stress response proteins, such as GroEL and HslU (13). This kind of stress response has been reported during metabolism of aromatics such as 2,4-dichlorophenoxyacetic acid by Burkholderia sp. strain YK-2 (10), biphenyl by Pseudomonas sp. strain B4 (8), and 4-chlorophenol by Ochrobactrum anthropi (42); in the latter two, an increase of reactive oxygen species due to oxygenase activity was measured. The stress responses observed in the wild-type cells, except for that involving the PrkA serine kinase, seemed to be mitigated in the mutant strains. However, we suggest that an alternative sigmaE-dependent stress response which originated from damage to the outer membrane caused by reactive oxygen species was present in the LB400 mutants when they were forced to use the box pathways during well-aerated exponential growth on benzoate. We reach this conclusion because we observed up-regulation of the following: (i) sigmaE, an extracytoplasmic function sigma factor activated in response to misfolded outer membrane proteins (1) and previously shown to be involved in oxidative stress response (43); (ii) a range of genes previously shown to be transcribed in a sigmaE-dependent manner (15), including sig$\mathrm{maH}$ and those coding for EPS production and pyoverdine biosynthesis (35); (iii) tol genes, which are involved in outer membrane stability (26); and (iv) cytochrome $o$ ubiquinol oxidase $(c y o)$, previously linked to protection against oxidative stress (25). The mitigation of the regular aerobic aromatic metabolism-associated stress response and the appearance of the extensive sigmaE-mediated oxidative stress response are presumably due to a different type or extent of damage than that occurring when LB400 expresses the pathways according to its normal signal transduction network.

The dissolved oxygen tension is an important factor influencing growth kinetics on aromatic substrates $(3,23,39)$. It has been suggested that the relatively high $K_{m}$ values for oxygen of the ring cleavage dioxygenases, e.g., catechol-1,2-dioxygenase, are responsible for the growth rate reduction at reduced oxygen tensions (3). The box pathways utilize only half the amount of molecular oxygen used by the ben-cat pathway, due to the presence of a hydrolytic ring cleavage mechanism, which does not require molecular oxygen (16). On the basis of these different reaction mechanisms and the growth substrate- and growth-phase-dependent expression patterns monitored for wt LB400, we hypothesized that the box pathways are preferentially active at lower oxygen levels in LB400 $(12,13)$. Though they were not measured, reduced oxygen tensions can be expected when multiple dioxygenases are active (e.g., during biphenyl metabolism) or at high cell densities at the end of growth. The extensive sigmaE-mediated oxidative stress response seen when the expression of box pathways was abnormally forced is in line with this hypothesis.

In conclusion, using a combined approach of genetics, transcriptomics, and proteomics, we showed that all three presumed benzoate pathways in LB400 are indeed able to degrade benzoate. Though some differences in substrate ranges were observed, the full extent to which these pathways differ with respect to their substrate specificities remains unclear. However, it is clear that such differences do not directly contribute to LB400's potency to degrade PCBs. We also provided conclusive data that the $\mathrm{C}_{1}$ metabolic pathway, specifically ex- pressed in transition-phase biphenyl-grown cells, is not induced by the production of formate during box pathway activity. This study also provided further proof of the complex interconnected regulatory network controlling aromatic catabolic pathway expression in LB400. Finally, the hypothesis that the box pathways are regulated to be expressed only at reduced oxygen levels was supported by the extensive oxidative stress response when the use of these pathways during well-aerated exponential growth on benzoate was forced.

\section{ACKNOWLEDGMENTS}

This work was supported by the Superfund Basic Research Program grant P42 ES 04911-12 from the U.S. National Institute of Environmental Health Sciences, by the Genomics:GTL program of the U.S. Department of Energy, by Genome British Columbia, and by Genome Canada. Vincent Denef received financial support from the Fund for Scientific Research-Flanders, Belgium (FWO-Vlaanderen).

We acknowledge Christopher Marx and William Metcalf for donation of strains and plasmids for genetics as well as for helpful discussions. Mary Beth Leigh is acknowledged for assistance with HPLC, Michael Weigand for technical assistance, and Benli Chai for bioinformatic support. We also acknowledge the anonymous reviewers for their helpful suggestions.

\section{REFERENCES}

1. Ades, S. E. 2004. Control of the alternative sigma factor sigmaE in Escherichia coli. Curr. Opin. Microbiol. 7:157-162.

2. Alexeyev, M. F. 1999. The pKNOCK series of broad-host-range mobilizable suicide vectors for gene knockout and targeted DNA insertion into the chromosome of gram-negative bacteria. BioTechniques 26:824-828.

3. Arras, T., J. Schirawski, and G. Unden. 1998. Availability of $\mathrm{O}_{2}$ as a substrate in the cytoplasm of bacteria under aerobic and microaerobic conditions. J. Bacteriol. 180:2133-2136.

4. Bedard, D. L., R. Unterman, L. H. Bopp, M. J. Brennan, M. L. Haberl, and C. Johnson. 1986. Rapid assay for screening and characterizing microorganisms for the ability to degrade polychlorinated biphenyls. Appl. Environ. Microbiol. 4:761-768

5. Blom, A., W. Harder, and A. Matin. 1991. Unique and overlapping pollutant stress proteins of Escherichia coli. Appl. Environ. Microbiol. 58:331-334.

6. Bopp, L. H. 1986. Degradation of highly chlorinated PCBs by Pseudomonas strain LB400. J. Ind. Microbiol. 1:23-29.

7. Cases, I., and V. de Lorenzo. 2001. The black cat/white cat principle of signal integration in bacterial promoters. EMBO J. 20:1-11.

8. Chavez, F. P., H. Lunsdorf, and C. A. Jerez. 2004. Growth of polychlorinated-biphenyl-degrading bacteria in the presence of biphenyl and chlorobiphenyls generates oxidative stress and massive accumulation of inorganic polyphosphate. Appl. Environ. Microbiol. 70:3064-3072.

9. Chen, J., S. M. Lee, and Y. Mao. 2004. Protective effect of exopolysaccharide colanic acid of Escherichia coli O157:H7 to osmotic and oxidative stress. Int. J. Food Microbiol. 93:281-286.

10. Cho, Y.-S., S.-H. Park, C.-K. Kim, and K.-H. Oh. 2000. Induction of stress shock proteins DnaK and GroEL by phenoxyherbicide 2,4-D in Burkholderia sp. YK-2 isolated from rice field. Curr. Microbiol. 41:33-38.

11. Dai, S., F. H. Vaillancourt, H. Maarouf, N. M. Drouin, D. B. Neau, V. Snieckus, J. T. Bolin, and L. D. Eltis. 2002. Identification and analysis of a bottleneck in PCB biodegradation. Nat. Struct. Biol. 9:934-939.

12. Denef, V. J., J. Park, T. V. Tsoi, J. M. Rouillard, H. Zhang, J. A. Wibbenmeyer, W. Verstraete, E. Gulari, S. A. Hashsham, and J. M. Tiedje. 2004 Biphenyl and benzoate metabolism in a genomic context: outlining genomewide metabolic networks in Burkholderia xenovorans LB400. Appl. Environ. Microbiol. 70:4961-4970.

13. Denef, V. J., M. A. Patrauchan, C. Florizone, J. Park, T. V. Tsoi, W. Verstraete, J. M. Tiedje, and L. D. Eltis. 2005. Growth substrate- and phase-specific expression of biphenyl, benzoate, and $\mathrm{C}_{1}$ metabolic pathways in Burkholderia xenovorans LB400. J. Bacteriol. 187:7996-8005.

14. Dudoit, S., Y. H. Yang, M. J. Callow, and T. P. Speed. 2002. Statistical methods for identifying genes with differential expression in replicated cDNA microarray experiments. Statistica Sinica 12:111-139.

15. Firoved, A. M., and V. Deretic. 2003. Microarray analysis of global gene expression in mucoid Pseudomonas aeruginosa. J. Bacteriol. 185:1071-1081.

16. Gescher, J., W. Eisenreich, J. Worth, A. Bacher, and G. Fuchs. 2005. Aerobic benzoyl-CoA catabolic pathway in Azoarcus evansii: studies on the nonoxygenolytic ring cleavage enzyme. Mol. Microbiol. 56:1586-1600.

17. Gescher, J., A. Zaar, M. Mohamed, H. Schägger, and G. Fuchs. 2002. Genes coding for a new pathway of aerobic benzoate metabolism in Azoarcus evansii. J. Bacteriol. 184:6301-6315. 
18. Goris, J., P. De Vos, J. Caballero-Mellado, J. Park, E. Falsen, J. F. Quensen III, J. M. Tiedje, and P. Vandamme. 2004. Classification of the PCB- and biphenyl-degrading strain LB400 and relatives as Burkholderia xenovorans sp. nov. Int. J. Syst. Evol. Microbiol. 54:1677-1681.

19. Haddock, J. D., L. M. Nadim, and D. T. Gibson. 1993. Oxidation of biphenyl by a multicomponent enzyme system from Pseudomonas sp. strain LB400. J. Bacteriol. 175:395-400.

20. Harwood, C. S., and R. E. Parales. 1996. The beta-ketoadipate pathway and the biology of self-identity. Annu. Rev. Microbiol. 50:553-590.

21. King, G. M. 2003. Molecular and culture-based analyses of aerobic carbon monoxide oxidizer diversity. Appl. Environ. Microbiol. 69:7257-7265.

22. Kitagawa, W., A. Suzuki, T. Hoaki, E. Masai, and M. Fukuda. 2001. Multiplicity of aromatic ring hydroxylation dioxygenase genes in a strong PCB degrader, Rhodococcus sp. strain RHA1 demonstrated by denaturing gradient gel electrophoresis. Biosci. Biotechnol. Biochem. 65:1907-1911.

23. Krooneman, J., E. R. B. Moore, J. C. L. van Velzen, R. A. Prins, L. J. Forney, and J. C. Gottschal. 1998. Competition for oxygen and 3-chlorobenzoate between two aerobic bacteria using different degradation pathways. FEMS Microbiol. Ecol. 26:171-179.

24. Laemmli, C., C. Werlen, and J. R. van der Meer. 2004. Mutation analysis of the different $t f d$ genes for degradation of chloroaromatic compounds in Ralstonia eutropha JMP134. Arch. Microbiol. 181:112-121.

25. Lindqvist, A., J. Membrillo-Hernandez, R. K. Poole, and G. M. Cook. 2000. Roles of respiratory oxidases in protecting Escherichia coli K12 from oxidative stress. Antonie Leeuwenhoek 78:23-31.

26. Llamas, M. A., J. L. Ramos, and J. J. Rodriguez-Herva. 2000. Mutations in each of the tol genes of Pseudomonas putida reveal that they are critical for maintenance of outer membrane stability. J. Bacteriol. 182:4764-4772.

27. Loprasert, S., R. Sallabhan, W. Whangsuk, and S. Mongkolsuk. 2003. Compensatory increase in $\operatorname{ahpC}$ gene expression and its role in protecting Burkholderia pseudomallei against reactive nitrogen intermediates. Arch. Microbiol. 180:498-502.

28. Maltseva, O. V., T. V. Tsoi, J. F. Quensen III, M. Fukuda, and J. M. Tiedje. 1999. Degradation of anaerobic reductive dechlorination products of Aroclor 1242 by four aerobic bacteria. Biodegradation 10:363-371.

29. Marx, C. J., and M. E. Lidstrom. 2002. Broad-host-range cre-lox system for antibiotic marker recycling in Gram-negative bacteria. BioTechniques 33: 1062-1067.

30. Marx, C. J., J. A. Miller, L. Chistoserdova, and M. E. Lidstrom. 2004 Multiple formaldehyde oxidation/detoxification pathways in Burkholderia fungorum LB400. J. Bacteriol. 186:2173-2178.

31. Miller, V. L., and J. J. Mekalanos. 1988. A novel suicide vector and its use in construction of insertion mutations: osmoregulation of outer membrane proteins and virulence determinants in Vibrio cholerae requires toxR. J. Bacteriol. 170:2575-2583.

32. Mohamed, M. E., A. Zaar, C. Ebenau-Jehle, and G. Fuchs. 2001. Reinvestigation of a new type of aerobic benzoate metabolism in the proteobacterium Azoarcus evansii. J. Bacteriol. 183:1899-1908.

33. Mondello, F. J. 1989. Cloning and expression in Escherichia coli of Pseudo- monas strain LB400 genes encoding polychlorinated biphenyl degradation. J. Bacteriol. 171:1725-1732.

34. Patrauchan, M. A., C. Florizone, M. Dosanjh, W. W. Mohn, J. Davies, and L. D. Eltis. 2005. Catabolism of benzoate and phthalate in Rhodococcus sp. strain RHA1: redundancies and convergence. J. Bacteriol. 187:4050-4063.

35. Ravel, J., and P. Cornelis. 2003. Genomics of pyoverdine-mediated iron uptake in pseudomonads. Trends Microbiol. 11:195-200.

36. Rodrigues, J. L. M., O. V. Maltseva, T. V. Tsoi, R. R. Helton, J. F. Quensen III, M. Fukuda, and J. M. Tiedje. 2001. Development of a Rhodococcus recombinant strain for degradation of products from anaerobic dechlorination of PCBs. Environ. Sci. Technol. 35:663-668.

37. Ruff, J., K. Denger, and A. M. Cook. 2003. Sulphoacetaldehyde acetyltransferase yields acetyl phosphate: purification from Alcaligenes defragrans and gene clusters in taurine degradation. Biochem. J. 369:275-285.

38. Seeger, M., K. N. Timmis, and B. Hofer. 1995. Conversion of chlorobiphenyls into phenylhexadienoates and benzoates by the enzymes of the upper pathway for polychlorobiphenyl degradation encoded by the bph locus of Pseudomonas sp. strain LB400. Appl. Environ. Microbiol. 61:2654-2658.

39. Shaler, T., and G. Klecka. 1986. Effects of dissolved oxygen concentration on biodegradation of 2,4-dichlorophenoxyacetic acid. Appl. Environ. Microbiol. 51:950-955.

40. Smith, D. J., V. J. Martin, and W. W. Mohn. 2004. A cytochrome P450 involved in the metabolism of abietane diterpenoids by Pseudomonas abietaniphila BKME-9. J. Bacteriol. 186:3631-3639.

41. Soballe, B., and R. K. Poole. 2000. Ubiquinone limits oxidative stress in Escherichia coli. Microbiology 146:787-796.

42. Tamburro, A., I. Robuffo, H. J. Heipieper, N. Allocati, D. Rotilio, C. Di Ilio, and B. Favaloro. 2004. Expression of glutathione S-transferase and peptide methionine sulphoxide reductase in Ochrobactrum anthropi is correlated to the production of reactive oxygen species caused by aromatic substrates. FEMS Microbiol. Lett. 241:151-156.

43. Testerman, T. L., A. Vazquez-Torres, Y. Xu, J. Jones-Carson, S. J. Libby, and F. C. Fang. 2002. The alternative sigma factor sigmaE controls antioxidant defences required for Salmonella virulence and stationary-phase survival. Mol. Microbiol. 43:771-782.

44. van der Meer, J. R., and V. Sentchillo. 2003. Genomic islands and the evolution of catabolic pathways in bacteria. Curr. Opin. Biotechnol. 14:248 254.

45. Vercellone-Smith, P., and D. S. Herson. 1997. Toluene elicits a carbon starvation response in Pseudomonas putida $\mathrm{mt}-2$ containing the TOL plasmid pWW0. Appl. Environ. Microbiol. 63:1925-1932.

46. Zaar, A., W. Eisenreich, A. Bacher, and G. Fuchs. 2001. A novel pathway of aerobic benzoate catabolism in the bacteria Azoarcus evansii and Bacillus stearothermophilus. J. Biol. Chem. 276:24997-25004.

47. Zaar, A., J. Gescher, W. Eisenreich, A. Bacher, and G. Fuchs. 2004. New enzymes involved in aerobic benzoate metabolism in Azoarcus evansii. Mol. Microbiol. 54:223-238.

48. Zaitsev, G. M., and Y. N. Karasevich. 1985. Primary steps in metabolism of 4-chlorobenzoate in Arthrobacter globiformis. Mikrobiologiya 50:423-428. 